\title{
A AÇÃo Pedagógica e A AUTOEFICÁCIA DOCENTE NO ENSINO SUPERIOR
}

\section{The pedagogical aCtion ANd TEACHER SELF-EFfiCACY IN HIGHER EDUCATION}

\author{
Fátima Cristina Luiz Leonardo \\ Mestre em Educação pela Universidade do Oeste Paulista, Presidente Prudente, SP - Brasil \\ ORCID: https://orcid.org/0000-0002-2952-1542 \\ faleonardo@unoeste.br \\ Camélia Santina Murgo \\ Doutora em Psicologia pela Pontifícia Universidade Católica de Campinas \\ Professora do Programa de Pós-Graduaçáo em Educaçẫo da Universi- \\ dade do Oeste Paulista, Presidente Prudente, SP - Brasil \\ ORCID: https://orcid.org/0000-0003-3932-7580 \\ cameliaprof@gmail.com
}

Bárbara Cristina Soares Sena Mestre em Educação pela Universidade do Oeste Paulista, Presidente Prudente, SP - Brasil ORCID: https://orcid.org/0000-0002-0164-7004 barbara_kristina08@hotmail.com

Resumo: Este estudo teve como objetivo compreender a percepção de autoeficácia de professores em suas práticas pedagógicas. Participaram nove docentes, de ambos os sexos, com idade entre 28 e 63 anos, de uma universidade particular do estado de São Paulo. Para a coleta de dados foram realizados encontros de grupo focal. A primeira categoria de análise mostrou que os professores identificam a interferência das três fontes de formação de crenças preconizadas pela literatura. Mencionam que tanto as aprendizagens vicárias quanto as experiências pessoais em sala de aula, bem como o feedback que recebem dos superiores, pares e dos próprios alunos, atuam como fontes de formação das suas crenças de autoeficácia. Já a segunda categoria revelou que os professores associam suas práticas pedagógicas a suas crenças de autoeficácia. Novos estudos são recomendados para que a compreensão acerca dos impactos da autoeficácia na ação docente seja mais bem dimensionada e, com isso, possam ser viabilizadas práticas pedagógicas exitosas na educação superior.

Palavras-chave: Ação Docente. Autoeficácia. Ensino Superior.

Авsтract: This study aimed to understand the perception of teachers' self-efficacy in their pedagogical practices. Nine teachers of both sexes, aged between 28 and 63 , participated in a private university in the state of Sáo Paulo. Focal group meetings were held to collect data. The first category of analysis showed that teachers identify the interference of the three sources of belief formation advocated in the literature. They 
mention that both vicarious learning and personal experiences in the classroom, as well as the feedback they receive from superiors, peers, and the students themselves, act as sources of training for their self-efficacy beliefs. The second category, however, revealed that teachers associate their pedagogical practices with their beliefs of self-efficacy. New studies are recommended so that the understanding about the impacts of self-efficacy on teaching action is better sized and, with this, successful pedagogical practices in higher education can be made possible.

KEYwords: Teaching Action. Self-Efficacy. Higher Education.

\section{Introdução}

A Teoria Social Cognitiva focaliza o desenvolvimento e a açáo humana na ótica de uma relação recíproca que ocorre entre o homem, os fatores pessoais e os fatores ambientais. Defende que o sujeito tem a oportunidade de interferir em seu ambiente, modificando-o e sendo por ele modificado (BERNARDINI, 2017). Desse modo, o sujeito desempenha influência sobre suas açôes, estabelecidas por fatores interativos, e, assim, contribui para o que acontece com ele, mas não determina os eventos que acontecem. (BANDURA, 1986, p.25)

A autoeficácia constitui um dos pilares centrais da Teoria Social Cognitiva, que a definiu como a crença que o sujeito tem na sua capacidade de realizar determinadas tarefas (IAOCHITE et al., 2016). As crenças indicam se os sujeitos pensam de modo produtivo, pessimista ou otimista, e o quanto conseguem motivar a si mesmos e persistir diante das dificuldades e das tomadas de decisão que fazem durante a vida (SHAUGHNESSY, 2004). Com isso, a expectativa de autoeficácia interfere diretamente nas escolhas de metas, na persistência, nas estratégias de prevenção em situaçôes adversas e no nível de comprometimento para realizá-las. (NUNES, 2007, p.32)

No que se refere ao processo de ensino e aprendizagem, ela opera como um preditor do sucesso acadêmico, pois quanto maior a crença de autoeficácia do docente, mais apropriada será a definição das estratégias de ensino, as explicaçóes referentes ao conteúdo, o controle da sala de aula, os métodos de enfrentamento e o empenho diante de situações difíceis, como também o entusiasmo e compromisso com o trabalho (AZZI; POLYDORO; BZUNECK, 2006). Observa-se ainda que a investigação 
da autoeficácia no ambiente educacional pode auxiliar na compreensão das estratégias de ensino e aprendizagem, aspectos que são essenciais para entender se as crenças de autoeficácia afetam a forma de aplicação de estratégias de aprendizagem visando o desenvolvimento de todos os alunos.

Nessa direção, Bandura (1986) explica que as crenças de autoeficácia fazem com que os docentes estipulem metas e objetivos para si mesmos, busquem desafios maiores, assim como intervém no grau de esforço que eles aplicarão nas atividades. A percepção de autoeficácia também interfere no nível de persistência, mesmo diante das dificuldades, como também influencia no modo como o docente reagirá diante dos fracassos eventuais da vida profissional. Em síntese, as crenças definem a forma como os docentes organizam suas açóes e o quanto se sentem capazes no engajamento de práticas educativas. (PAJARES; OLAZ, 2008; IAOCHITE et al., 2016)

Com base nessas premissas teóricas, compreende-se a autoeficácia docente como o julgamento que o professor faz sobre sua capacidade de atingir resultados relacionados aos processos de ensino e aprendizagem. Essas crenças de autoeficácia tendem a influenciar significativamente as açóes pedagógicas e profissionais, visto que se relaciona com a maneira com que o professor percebe a profissáo, organiza suas aulas e até mesmo a concepçáo de que todos os seus alunos possuem capacidade de aprender, mesmo em situações de dificuldades de aprendizagem (IAOCHITE et al., 2016; RAMOS et al., 2016). De forma geral, crenças elevadas de autoeficácia dos docentes aparecem associadas com um melhor desempenho dos alunos em várias disciplinas focalizadas; um crescimento da autoeficácia acadêmica dos próprios estudantes, quando considerada como variável sua motivação; uma adesão a estratégias mais adequadas para trabalhar com os alunos, especialmente os "alunos-problema" (RAMOS et al., 2016). E, de modo contrário, docentes com avaliaçóes mais baixas de autoeficácia tendem a evitar atividades e até mesmo planejamento quando consideram estas acima de suas capacidades, e são menos persistentes na forma de lidar com alunos portadores de dificuldades. (SCHUNK, 1991; RAMOS et al., 2016)

Assim, conhecer as crenças dos professores constitui elemento fundamental para a promoção e facilitação da formação docente no ensino superior, uma vez que influenciam as escolhas dos cursos de ação tomados, o quanto de energia investirão para consecução dos objetivos, por quanto 
tempo irão perseverar em face de obstáculos e fracassos, sua resiliência à adversidade, os padrôes de pensamento de autoimpedimento ou de autossuporte, e o quanto de estresse e depressão vivenciarão com demandas do ambiente. (IAOCHITE, 2014)

Convém ressaltar que as crenças de autoeficácia são constituídas a partir das perspectivas de conhecimentos obtidas por quatro fontes de formação, a saber: experiência pessoal, aprendizagem vicária, persuasão verbal e indicadores fisiológicos (BANDURA, 1997; RAMOS et al., 2017). Essas fontes operam de forma conjunta, considerando-se que se afetam entre si, mas em determinados momentos uma delas pode ter influência maior do que as outras, dependendo da força que cada fonte terá para a pessoa. (NUNES, 2008)

A fonte experiência pessoal consolida-se por meio da interpretação de experiências prévias, isto é, as próprias experiências de sucesso ou fracasso vivenciadas pelo indivíduo, de modo que elas são utilizadas para desenvolver ou manter crenças sobre a capacidade de se envolver em determinadas atividades que posteriormente influenciarão a motivação e a persistência para o envolvimento em tarefas do mesmo âmbito (BERNARDINI, 2017). Essa fonte é apontada como a de maior influência na formação das crenças, visto que é baseada em uma experiência de sucesso verdadeiro. É que o sucesso em certas ações tende a elevar ou reforçar a percepção de eficácia pessoal, sendo que, por outro lado, o fracasso replicado pode diminuir a crença de autoeficácia, principalmente quando ocorre cedo no percurso dos eventos e quando não retrata falta de esforços ou condiçóes externas adversas. (BANDURA, 1986)

Outra fonte de formação das crenças de autoeficácia é a aprendizagem vicária, representada pela observação de outros sujeitos realizando certas atividades. Observar outras pessoas semelhantes com sucesso em suas açóes tende a aumentar a autoeficácia do observador por meio da informação inferencial de que o sujeito também será capaz de agir com sucesso em situações similares. (PAJARES, 2002; BERNARDINI, 2017)

Por fim, a fonte de persuasão verbal diz respeito ao feedback avaliativo, que pode causar elevação ou rebaixamento da autoeficácia. Quando os sujeitos são informados de que dispóem de capacidades para realizar uma atividade específica, provavelmente movimentam um esforço maior para executá-la (BERNARDINI, 2017). A influência da persua- 
são verbal está ligada à credibilidade de quem infere e ao domínio sobre o conhecimento das açóes; com isso, a influência da persuasão será tão forte quanto a confiança de quem observa a pessoa que está persuadindo. (BANDURA, 1997)

A última fonte, denominada indicadores fisiológicos, representa a avaliação feita pelos próprios sujeitos do seu estado físico e emocional ao executar determinada ação (BERNARDINI, 2017). Os indivíduos geralmente percebem sua ativação fisiológica em eventos estressantes ou que demandem indicadores de vulnerabilidades (BANDURA, 1986; 1997). Um ótimo grau de reação fisiológica depende, segundo Bandura (1997), não somente da natureza da atividade, mas também das inferências causais sobre a reação. Uma pessoa inclinada a perceber suas reações fisiológicas como sinal de inadequação pessoal é mais suscetível a sofrer uma baixa na percepção de autoeficácia, diferentemente daquela que analisa suas reaçóes como transitórias e comuns em situaçáo de tensão, mesmo nos mais experientes naquele domínio.

No contexto educacional, as crenças de autoeficácia tanto de professores quanto de alunos encontram-se entre as mais estudadas e fazem parte do conjunto de muitas outras crenças que influenciam, significativamente, o que e como um indivíduo percebe, compreende, aprende e realiza suas ações (KAGAN, 1992; PAJARES, 2002). Em razão disso, visando a importância das crenças de autoeficácia demonstrada pela literatura, considerou-se essencial no presente estudo buscar compreender se elas interferem nas açóes dos docentes que atuam no ensino superior.

Estudos sobre a autoeficácia docente e suas implicaçôes no ensino vêm sendo realizados no cenário nacional e internacional e apresentam crescimento nos últimos anos. A esse respeito, Tschannen-Moran, Woolfolk Hoy e Hoy (1998) desenvolveram um levantamento entre os anos de 1974 e 1997 no qual realizaram uma revisão de investigações em que aparece o constructo autoeficácia docente. Os autores concluíram que a autoeficácia do docente se relaciona não apenas com os resultados dos alunos quanto ao seu rendimento e motivação, mas também se vincula aos comportamentos que os alunos manifestam em sala de aula. De forma geral, os professores com maior crença de autoeficácia demonstram mais abertura a novas ideias, estão mais dispostos a provar novos métodos que se adéquem de maneira mais satisfatória às necessidades dos alunos, plane- 
jam e organizam melhor suas aulas e se encontram mais comprometidos com sua profissão.

Ressaltando alguns estudos que pesquisaram a autoeficácia de professores no ensino superior, pode ser mencionado o de Bailey (1999). Em pesquisa com 207 docentes, sendo 141 bacharéis, 39 mestres e 27 doutores, o autor focou a motivação e a autoeficácia para o ensino e a pesquisa. Verificou-se que alguns professores possuem motivação e autoeficácia mais reduzidas para pesquisa, o que, segundo o autor, pode ser justificado devido a importância e ao incentivo que cada faculdade oferece aos profissionais que se dedicam a esta área. Portanto, docentes de instituições com foco maior na graduação, tendem a demonstrar uma maior motivação e autoeficácia para o ensino e um rebaixamente no que se refere à pesquisa.

Outro estudo, este realizado por Navarro (2005), focalizou as crenças de autoeficácia do professor universitário. Em uma amostra de 362 docentes que pertenciam a 14 universidades espanholas, sendo dez públicas e quatro privadas, a autora discorre que se os professores ensinam em função de suas crenças de autoeficácia docente é viável intervir no âmbito de suas crenças de modo a instaurar, fortalecer ou até mesmo mudar seus sentimentos de autoeficácia para o ensino. Essas melhoras previsivelmente ocasionariam uma docência mais eficaz, voltada a favorecer a qualidade da aprendizagem do aluno.

Em síntese, os estudos realizados nos últimos anos vêm sinalizando que as crenças de autoeficácia do professor podem influenciar e determinar o processo de organização das práticas docentes, o que justifica o objetivo desta pesquisa, a saber, compreender a percepção de autoeficácia dos docentes de uma instituição de ensino superior, com foco nas implicações das crenças de autoeficácia na seleção de suas estratégias pedagógicas.

\section{Metodologia}

Participaram deste estudo nove professores de uma IES particular do interior do Estado de São Paulo, sendo três do sexo masculino e seis do sexo feminino, com idades entre 28 a 63 anos. Os participantes ministram disciplinas nos cursos de: Direito, Recursos Humanos, Administração, 
Gestão Comercial, Informática, Estética, Educação Física e Letras. Desses docentes, o que tem menor tempo de atuação soma dois anos e o que tem maior tempo tem quatorze anos de exercício profissional na instituição. No que se refere à titulação, quatro são mestres, dois são doutorandos e três são doutores. Seguindo os termos éticos, os nomes dos participantes foram trocados para preservar o anonimato.

Para coleta de dados foi escolhida a técnica de grupo focal, que segundo Morgan e Krueger (1993) têm por objetivo captar, a partir das trocas realizadas no grupo, conceitos, sentimentos, atitudes, crenças, experiências e reaçóes de um modo que náo seria possível com outros métodos, como a observação, a entrevista ou os questionários. O grupo focal permite fazer emergir uma multiplicidade de pontos de vista e processos emocionais pelo próprio contexto de interação criado, resultando na captação de significados que com outros meios poderia ser difícil trazer à tona.

Os grupos tiveram duração de uma hora e meia, em que a pesquisadora atuou como moderadora e utilizou o espaço para esclarecer dúvidas e aprofundar-se nas questóes levantadas, proporcionando um ambiente interativo e promovendo a pluralização de ideias. Nos encontros discutiuse o conceito de autoeficácia, as crenças e as suas fontes de formação e a autoeficácia nas ações pedagógicas e práticas docentes.

Quanto à análise dos dados, foi empregada a Análise de Conteúdo, conceituada por Bardin (2009) como um conjunto de técnicas de investigação que procura identificar e categorizar as principais ideias em um determinado tema. Inicia-se por uma leitura flutuante, a partir do estabelecimento de categorias e análises de indicadores, com objetivo de classificar as semelhanças nas falas, possibilitando a interpretação dos resultados. Assim, a partir do critério de semelhança entre as respostas, organizam-se categorias de análise.

\section{Resultados e discussão}

A fim de explorar os dados coletados, buscou-se discutir as respostas apresentadas pelos professores no processo de grupo focal de forma que fossem explicitadas as açôes que eles têm empreendido no ensino superior. 
Para tanto, foram organizadas duas grandes categorias de análise, a saber: Fontes de formação de crenças e Associações entre crenças de autoeficácia e ação docente.

\section{Categoria 1 - Fontes de formaçáo de crenças}

O processo de ensino é entendido como um seguimento educacional complexo, que exige uma adequada compreensão da motivação e dos comportamentos dos professores (BZUNECK, 1996). Para tanto, o conhecimento das crenças de autoeficácia docente torna-se indispensável, visto que elas podem ser preditoras do empenho que o sujeito irá despender em suas açóes, a perseverança diante dos obstáculos e sua resiliência, influenciando as experiências de sucesso ou fracasso.

No que se refere às fontes de formação de crenças, Bandura (1986) descreve que na autoavaliação de eficácia, há muitas fontes de informação que devem ser processadas, medidas e ponderadas com base em pensamentos autorreferentes. Descreve ainda que somos acometidos por quatro fontes: Experiências Diretas e Pessoais; Experiências Vicariantes; Persuasão Verbal ou Social e Estados Fisiológicos e Emocionais. (PAJARES, 1996; BERNARDINI, 2017)

$\mathrm{Na}$ intenção de conferir visibilidade ao conjunto de verbalizaçôes fornecidas pelos professores quanto à autoeficácia, foi utilizado o recurso de nuvem de palavras, para mostrar a prevalência de palavras associadas aos relatos dos docentes, bem como identificar a interferência das fontes na formação de suas crenças.

Pode-se observar, pela imagem, que nas falas dos docentes as palavras que apareceram em maior destaque foram as que remetem ao que é associado às fontes de formação, tais como: a palavra vejo e capaz, que faz alusão à fonte Aprendizagem Vicária, que corresponde à observação de outra pessoa-modelo; as palavras resolver e experiências também surgem com frequência, reportando à fonte Experiências Diretas, em que o sujeito avalia suas próprias vivências na resolução de tarefas. A fonte Persuasão verbal também aparece com relevância na repetição da palavra feedback, que tem relação com as verbalizaçóes recebidas de terceiros sobre sua capacidade de sucesso. 


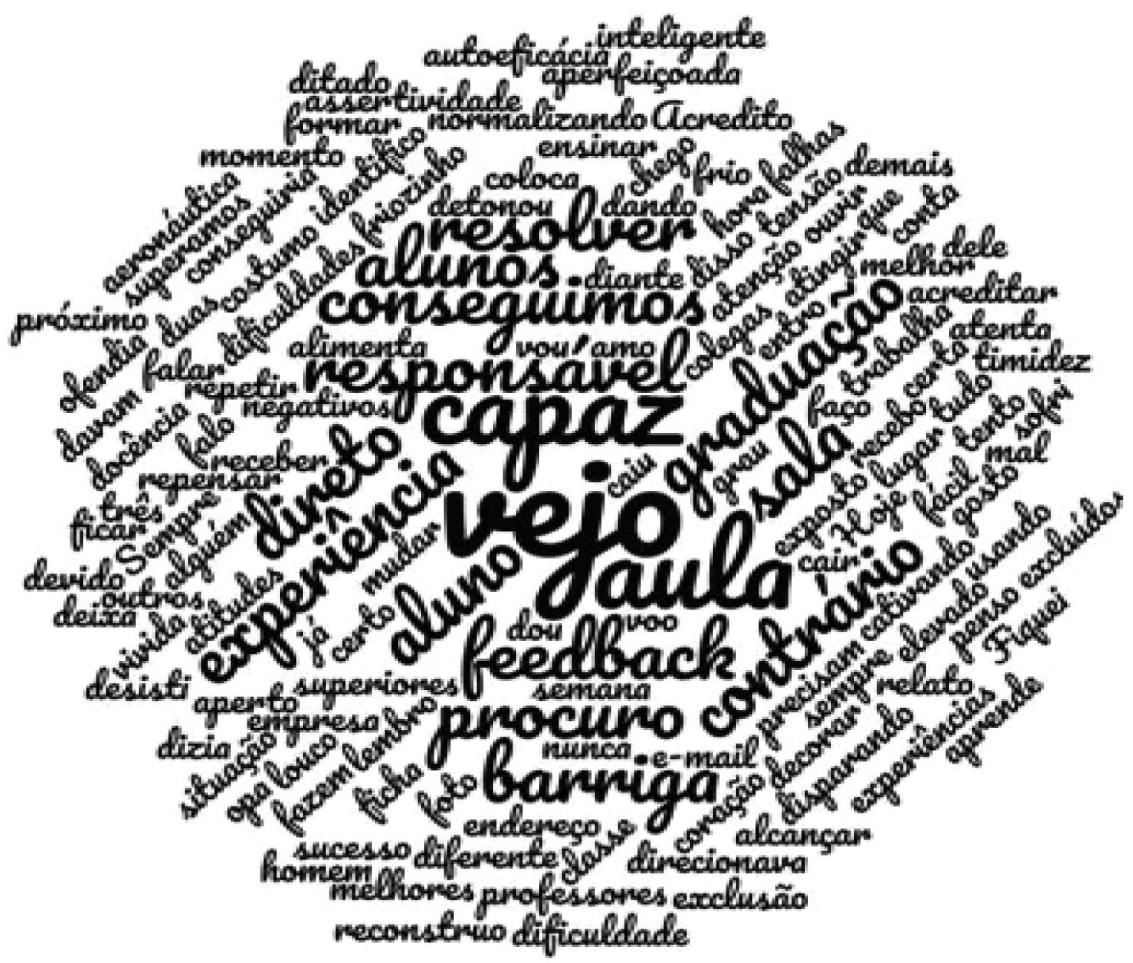

Figura 1: Nuvem de palavras: Fontes de formação de crenças de autoeficácia

Fonte: autoras.

Cabe ressaltar que as Experiências Diretas são tidas como a principal fonte de influência da autoeficácia, constituindo-se pela interpretação dos resultados de suas próprias vivências anteriores (BERNARDINI, 2017). Os docentes podem, a partir dessas experiências, reforçar as próprias percepçóes que possuem mediante os efeitos da sua ação, fortalecendo ou rebaixando a crença. Portanto, nesta pesquisa, quando o professor diz que se reconstrói, aprende com os seus erros, vai em busca do aprendizado, ele está revelando que sofre interferências da fonte Experiências Diretas e Pessoais. De acordo com Bandura (1989), a autoeficácia é um fator que desempenha um importante papel na motivação; é parcialmente com base nas crenças de autoeficácia que as pessoas escolhem de quais desafios to- 
mar parte (definição de metas ou objetivos), quanto esforço despender e o quanto perseverar em face das dificuldades encontradas. Quando as pessoas se percebem autoeficazes, se sentem seguras e motivadas para realizar seus projetos. (IAOCHITE et al., 2016)

Já as Aprendizagens Vicárias remetem a como a pessoa interpreta as açôes de outras, buscando um modelo que pode indicar estratégias bemsucedidas, ou até mesmo repelir algumas atitudes, em decorrência de um exemplo que náo foi bem-sucedido (BERNARDINI, 2017; RAMOS et al., 2017). Em relação à pesquisa realizada, vários relatos dos participantes mencionam profissionais que se tornaram referência e com os quais aprenderam muito, por serem bons modelos de competência. Também foram relatadas experiências negativas observadas que náo tiveram bom êxito, nas quais os docentes indicam que usam essas observaçóes de modelos com resultados negativos como aprendizado para náo cometer o mesmo erro. Algumas verbalizaçóes dos professores ressaltam a identificação que mencionam sobre a fonte Experiências Vicárias:

"Eu gosto de ouvir relato de pessoas, tudo para mim é uma experiência, vejo o que os outros fazem e tento fazer o melhor." (Professor 1)

"No meu tempo de graduação, tive professores que sempre direcionavam a aula para duas ou três, que eram as melhores da sala, e eles só davam aula para elas, os demais, eram excluídos. Eu, devido a minha timidez, sofri muito, por essa exclusão. Então, tudo que eu tive de dificuldade na graduação, procuro fazer o contrário na sala de aula." (Professor2)

"Ver o que o outro fez, eu vejo direto, já tem um ditado que diz, inteligente é o homem que aprende com a experiência do próximo, opa, caiu ali, deixa eu ficar atenta para não cair também." (Professor 3)

A terceira fonte de formação de crenças, denominada Persuasão Verbal, é representada pelo retorno que se recebe do outro (BERNARDINI, 2017). Envolve o julgamento de outras pessoas e demonstra como elas es- 
tão avaliando um determinado trabalho. Respostas persuasivas positivas tendem a encorajar e motivar o indivíduo a determinadas açóes, tarefas e atividades. Sobre essa fonte, algumas verbalizaçôes dos professores merecem ser destacadas:

"Quando eu recebo o feedback de alguém, procuro repensar em minhas atitudes, e, aquilo que está dando certo, eu vou repetir." (Professor 4)

"Eu amo receber feedback. Isso me alimenta, mesmo os negativos, pois somente diante do exposto por seus colegas, superiores ou alunos, conseguimos mudar e atingir um grau mais elevado." (Professor3)

A Persuasão Verbal é tida como uma forma de reforçar as crenças das pessoas verbalmente acerca das capacidades necessárias para realizar determinadas atividades (MONTEIRO et al., 2016). Essa fonte pode tornar as pessoas mais suscetíveis a mobilizar maior esforço e mantê-lo, em comparação com aquelas que mantêm autodúvidas e se fixam nas limitaçôes pessoais quando surgem problemas. A Persuasão Social, além de conduzir a um maior rigor na tentativa de sucesso, promove o desenvolvimento de habilidades e de um senso de eficácia pessoal (BANDURA, 1997). Durante os encontros, os docentes apontaram a importância de receberem esse feedback, mas também citaram que nem todos estão preparados para ouvir, pois isso também exige um grau de maturidade para administrar as frustraçôes quando o resultado náo é bem-sucedido.

Finalmente, as crenças constituídas por interferência da fonte Estados Fisiológicos são utilizadas pelas pessoas como indicadores tanto para o êxito quanto para o fracasso no desempenho, visto que a percepção dos impulsos fisiológicos interfere nos estados emocionais no momento em que executam a ação (BERNARDINI, 2017; MONTEIRO et al., 2016). Por exemplo, sintomas físicos aversivos como dor de cabeça, frio na barriga e fadiga são apontados como indicadores de ineficiência. Frente à percepção de tais sinais fisiológicos, o indivíduo tende a confiar menos em sua capacidade para obter sucesso. Ao contrário, apresentam maior segurança em suas capacidades os indivíduos que se sentem em adequado estado de 
alerta. No caso dos docentes participantes, foi relatada essa interferência diária dos estados fisiológicos, principalmente no início de cada semestre. A esse respeito, os professores da pesquisa revelaram que:

"Sempre que vou falar, dá um friozinho na barriga, um aperto, coração disparando, depois vai normalizando.”(Professor5)

"Toda semana que ia na classe desse aluno, ia com uma certa tensão," (Professor6)

"Dá um frio na barriga, eu entro na ficha dos alunos, para ver o endereço do e-mail, tem muitos que coloca o e-mail da empresa, e já falo esse trabalha em tal lugar, e eu sempre vejo a foto, e na hora que chego e já identifico, costumo decorar o nome do aluno, ai você vai cativando, mas não é fácil não viu." (Professor2)

Considerando que as crenças de autoeficácia interferem nas açôes docentes, importa perceber em que medida os professores se sentem autoeficazes para a tarefa de empreender práticas pedagógicas que se mostrem promissoras na promoção do sucesso acadêmico de seus alunos. A esse respeito, serão discutidas, na categoria seguinte, aproximaçôes entre crenças e ações do professor.

\section{Categoria 2 - Associaçóes entre crenças de autoeficácia e açóes docentes}

Bandura (1997) explica que a autoeficácia implica nos julgamentos que cada indivíduo faz de suas capacidades para levar a cabo determinada tarefa ou desempenhar determinada atividade. Deve ser ressaltado que a autoeficácia é a crença que cada pessoa tem sobre a sua capacidade de fazer algo, o esforço que empenha para a realização de tarefas e a sua persistência perante o desafio e a qualidade da sua realização (IAOCHITE et al., 2016). Nessa direçáo, foi verificado com o grupo participante o quanto se percebiam autoeficazes em sua atuação docente. Inicialmente, os resultados serão representados na Figura 2. 


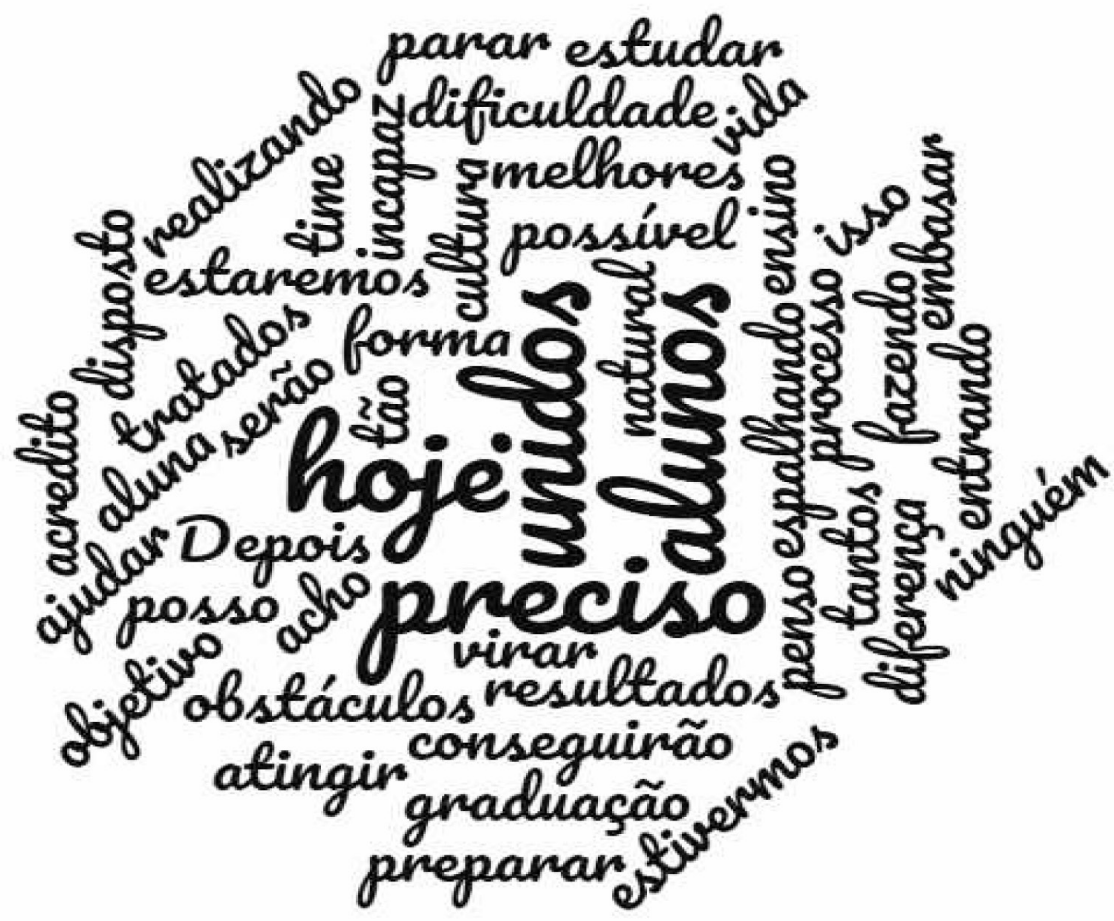

Figura 2: Nuvem de palavras: associaçôes entre crenças de autoeficácia e ações docentes

Fonte: autoras.

A Figura 2 demonstra a frequência com que determinadas palavras aparecem nos discursos dos participantes; dentre elas estão as seguintes: resultados, objetivo, processo, realizando, fazendo e ajuda. Essas palavras sugerem, quando são expressas por professores, que as experiências da prática docente se associam com a autoeficácia. A esse respeito, verificou-se que alguns docentes relataram situações de muita autoeficácia e outros, em alguns momentos, recuaram, dizendo que não foram autoeficazes em ocasiôes específicas, por exemplo em situações de inclusão, como segue nas falas abaixo: 
"E hoje, como tenho uma aluna que tem dificuldade, já penso, como posso fazer para ajudar a atingir nosso objetivo." (Professor 7)

"Eu preciso estudar para isso, eu preciso me preparar... ninguém tem tempo para parar para fazer isso. Então se todos nós estivermos unidos como estamos fazendo aqui hoje, embasar a sua vida, eu acho possível.” (Professor6)

"Depois que virar cultura, vai espalhando de forma táo natural, que todos estaremos unidos, realizando o processo de ensino sem tantos obstáculos, e os alunos conseguirão melhores resultados, pois não serão tratados como incapaz." (Professor2)

À medida que os docentes afirmam ser possível uma educação efetiva e que a capacitação e enfrentamento de obstáculos os tornariam capazes, revelam autoeficácia positiva, pois demonstram ter expectativas de resultados ligadas ao sucesso. Sobre isso, Pajares e Orlaz (2008) descrevem que as percepçóes que os indivíduos têm sobre suas capacidades constituem conteúdos atitudinais em relação à sua ação, que buscam superar expectativas que levem ao sucesso. Sendo assim, a autoeficácia atua como mediadora de práticas desses docentes, resultando no uso de novas estratégias de ensino e metodologias, e também em uma maior reflexão sobre as metas que estabelece e suas realizaçóes. (THOONEN; SLEEGERS; PEETSMA; OORT, 2011).

Ressalte-se, nessa definição de autoeficácia, que se trata de uma avaliação ou percepção pessoal quanto às próprias habilidades e conhecimentos, quando representados pelo termo capacidades. Então, a crença de autoeficácia não é relacionada a possuir ou náo tais capacidades, mas ao fato de a pessoa acreditar que as possua (IAOCHITE et al., 2016; BERNARDINI, 2017). Além disso, são capacidades direcionadas para organizar e executar linhas de ação, o que significa uma expectativa de "eu posso fazer" determinada ação, e não necessariamente acreditar ser capaz de ir bem em todos os domínios da vida.

Ainda é preciso levar em consideração que as crenças não atuam isoladamente, pois a autoeficácia é um constructo pessoal e social influen- 
ciado por outros fatores, que em conjunto aumentam ou diminuem a percepção de capacidade do sujeito (PAJARES; ORLAZ, 2008). Portanto, também se faz necessário analisar o contexto em que o docente exerce seu trabalho e que tipo de reconhecimento e recursos lhe são oferecidos; e mais: se o ambiente se torna positivo ou negativo em relação a sua prática e, consequentemente, as suas crenças de autoeficácia.

Por último, há um componente de finalidade, por contemplar exigências de uma dada situação que precisam ser cumpridas. Com isso, as pessoas, a partir da sua crença de autoeficácia, consideram simultaneamente as próprias potencialidades, o objetivo de atender às exigências da situação proposta e as ações que conduzam a esse objetivo (BZUNECK, 2002). É preciso que ao analisar todas as variáveis o docente encontre a finalidade para a qual sua prática é proposta, pois assim conseguirá estabelecer melhores metas e terá mais possibilidades de êxito ao final do trabalho.

Diante das análises expostas, entendemos que conhecer o tema da autoeficácia proporcionou aos docentes uma reflexão em relação à própria atuação, fazendo-os enxergar perspectivas positivas e possibilitando novas motivaçóes para a consecução das metas perseguidas, mesmo diante das limitaçóes e adversidades presentes no contexto profissional.

\section{Consideraçóes finais}

Esta pesquisa é uma demonstração da possibilidade de discussão e análise sobre a autoeficácia docente no ensino superior, com vistas a entender as potencialidades e adversidades que professores encontram diante de situações cotidianas no seu contexto de trabalho. Nesta pesquisa, o conjunto das análises realizadas permitiu sugerir que várias das dúvidas apresentadas pelos docentes na questão da autoeficácia são igualmente experimentadas pelos pares.

Compreende-se que as crenças de autoeficácia exercem influência em praticamente todos os aspectos da vida e que, independentemente da forma como se percebem - pessimista ou otimista, produtivo ou improdutivo, capaz ou incapaz - o sujeito, mediante suas crenças, irá delimitar seu meio de ação, seja este pela motivação e perseverança seja por estresses, desengajamento e desmotivação. (PAJARES; OLAZ, 2008) 
Diante do exposto, os resultados indicam, assim como a teoria, que os professores com um alto grau de sentido de eficácia no ensino atuam com a convicção de que os alunos são ensináveis a partir de um esforço suplementar e de técnicas apropriadas, e que conseguem atrair apoios familiares e superar as influências negativas da comunidade por meio de um ensino efetivo. Portanto, são profissionais que se engajam e encontram uma maior motivação na sua atividade profissional, o que, consequentemente, acarreta uma melhor prática pedagógica.

Por fim, considerou-se a experiência com grupo focal para a discussão da autoeficácia docente e suas ações pedagógicas como uma oportunidade positiva de compreensão das percepçôes que esses profissionais desenvolvem em seu ambiente profissional. Ainda assim, dadas as limitaçôes do estudo, ressalta-se a importância de novas investigaçôes que visem expandir a compreensão dos pontos abordados e que busquem a intervenção e respectivo peso de outros fatores que até o momento não foram investigados.

\section{Referências}

AZZI, R.G., POLYDORO, S.A.J., BZUNECK, J.A. Consideraçôes sobre a Autoeficácia Docente. In: AZZI, R.G. e POLYDORO, S.A.J. (org.) Auto-eficácia em diferentes contextos. Campinas, SP: Editora Alínea, 2006. p.149-159.

BAILEY, J. G. Academics' Motivation and Self-efficacy for Teaching and Research. Higher Education Research \& Development, v.18, n.3, p.343-359, 1999.

BANDURA, A. Self-efficacy: the exercise of control. New York: W. H. Freeman, 1997. BANDURA, A. Social foundations of thought and action: a social cognitive theory. New Jersey: Prentice- Hall Inc., Englewood Cliffs, 1986.

BANDURA, A. Regulation of cognitive processes through perceived self-efficacy. Developmental Psychology, 25,729-735, 1989.

BARDIN, L. Análise de conteúdo. Lisboa, Portugal; Edições 70, 2009.

BERNARDINI, P. Estudo correlacional sobre autoeficácia e Burnout no trabalho docente no ensino superior. 2017. 102 f. Dissertação (Mestrado em Educação) - Universidade do Oeste Paulista, Presidente Prudente, 2017. 
BZUNECK, J. A. Crenças de auto-eficácia de professoras do primeiro grau e sua relação com variáveis de predição e de contexto. Arquivos Brasileiros de Psicologia, 48, 67-89, 1996.

BZUNECK, J. A. A motivação do aluno: aspectos introdutórios. In: BORUCHOVITCH, E.; BZUNECK, J. A. (Orgs) Motivação do aluno. Petrópolis: Vozes, 2002. p. 9-36.

IAOCHITE, R. T. Crenças de eficácia docente e suas origens. Psicol. Ensino \& Form., Brasília, v. 5, n. 2, p. 81-102, 2014.

IAOCHITE, R. T et al. Autoeficácia no campo educacional: revisão das publicações em periódicos brasileiros. Psicol. Esc. Educ., Maringá, v. 20, n. 1, p. 45-54, abr. 2016.

KAGAN, D. M. Professional growth among preservice and beginning teachers. Review of Educational Research, v. 62, n. 2, p. 129-169, 1992.

MONTEIRO, A. C. et al. A crença da autoeficácia no contexto da avaliação psicopedagógica - um estudo de caso. Revista PsicoFAE: Pluralidades em Saúde Mental, [S.1.], v. 4, n. 1, p. 61-74, set. 2016.

MORGAN, D. L.; KRUEGER, R. A. When to use focus groups and why. In:

MORGAN, D. L. (Ed.), Sage focus editions, v.156. Successful focus groups: Advancing the state of the art (pp. 3-19). Thousand Oaks, CA, US: Sage Publications, Inc, 1993.

NAVARRO, L. P. As Crenças de Auto-eficácia Docente do Professorado Universitário. Tese de Doutorado, 2005.

NUNES, M. F. O. Escala de fontes de eficácia percebida: aplicação a jovens em escolha profissional. 2007. Dissertação (Mestrado) - Universidade de São Francisco, Itatiba, SP, 2007.

NUNES, M. F. O. Funcionamento e desenvolvimento das crenças de auto-eficácia: uma revisão. Revista Brasileira de Orientação Profissional, v. 9, n. 1, p. 29-42, 2008.

PAJARES, F. Overview of social cognitive theory and of self-efficacy. Social Cognitive Theory, 2002.

PAJARES, F. Role of self-efficacy beliefs in the mathematical problem-solving of gifted students. Contemporary Educational Psychology, v. 21, p. 325-344, 1996.

PAJARES, F.; OLAZ, F. Teoria social cognitiva e autoeficácia: Uma visão geral. In: BANDURA, A.; AZZI, R. G.; POLYDORO, S. A. J. et al. Teoria Social Cognitiva: conceitos básicos. 1. Ed. Porto Alegre: Artmed, 2008, p. 97-114.

RAMOS, M. F. H. et al. Caracterização das Pesquisas sobre Eficácia Coletiva Docente na Perspectiva da Teoria Social Cognitiva. Psic.: Teor. e Pesq., Brasília, v. 32, n. 1, p. 91-99, Mar. 2016. 
RAMOS, V. et al . Fontes de autoeficácia docente de universitários de educação física. J. Phys. Educ., Maringá, v. 28, e2829, 2017.

SCHUNK, D.H. Self-Efficacy and Academic Motivation. Educational Psychologist, v. 26, n. 3/4, p. 207-31, 1991.

SHAUGHNESSY, M. F. An interview with Anita Woolfolk: the educational psychology of teacher efficacy. Educational Psychology Review, v. 16, n. 2, p. 153-176, 2004.

THOONEN, E. E. J.; SLEEGERS, P. J. C.; PEETSMA, T. T. D.; OORT, F. J. Can Teachers Motivate Students to Learn? Educational Studies, v. 37, n. 3, p. 345-360, 2011.

TSCHANNEN-MORAN, M.; WOOLFOLK HOY, A.; HOY, W. K. Teacher efficacy: its meaning and measure. Review of Educational Research. v. 68, n. 2, p. 202-248, 1998.

Recebido em I7 set. 2017 / Aprovado em 2 jan. 2019

\section{Para referenciar este texto:}

LEONARDO, F. C. L.; MURGO, C. S.; SENA, B. C. S. A ação pedagógica e a autoeficácia docente no ensino superior. EccoS-Revista Científica, São Paulo, n. 48, p. 255-272. jan./mar. 20I9. Disponível em: <https://doi.org/I0.5585/EccoS.n48.8058>. 